\title{
Avaliação dos Riscos do Pregão Eletrônico: uma ABORDAGem PELA TeORIA da Nova ECONOMIA InStitucional
}

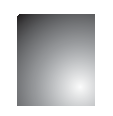

\author{
Risk Assessment of Electronic Bidding: an approach by the \\ Theory of New Institutional Economy
}

\author{
Evandro Rodrigues de Faria \\ Doutorando do Programa de Pós-Graduação e Pesquisas em Administração, Universidade Federal de Minas Gerais - Belo Horizonte - \\ MG - Brasil. E-mail: evandrozd@hotmail.com
}

\section{Marco Aurélio Marques Ferreira}

Doutor em Economia Aplicada pela Universidade Federal de Viçosa. Professor do Programa de Pós-Graduação em Administração. Universidade Federal de Viçosa - Viçosa - MG - Brasil. E-mail: marcoaurelio@ufv.br

\section{Márcio Augusto Gonçalves}

Doutor em Administração pela Aston University, Grã-Bretanha. Professor do Programa de Pós-Graduação e Pesquisas em Administração. Universidade Federal de Minas Gerais - Belo Horizonte -MG - Brasil. E-mail: marcio@cepead.face.ufmg.br

\section{Resumo}

A pesquisa investigou os fatores de riscos potencializados pela utilização do pregão eletrônico. Como fundamentação teórica foram utilizados os princípios da Teoria dos Custos de Transação (ECT). Foi realizada pesquisa exploratória e descritiva, de abordagem quantitativa, com o objetivo de classificar as empresas fornecedoras da União de acordo com o grau de risco apresentado aos contratos de fornecimento. Foram elaborados constructos de acordo com os princípios da ECT sendo validados pelo Alfa de Cronbach. Posteriormente foram realizadas análises fatoriais e de cluster. Através das análises realizadas foi possível classificar os fornecedores em três grupos: alto risco, baixo risco e risco moderado. Através dos resultados, conclui-se que os Órgãos Públicos devem criar salvaguardas contra atitudes oportunistas. Por isso é importante a especificação correta dos produtos para não dar margem para a cotação de produtos de qualidade inferior, e também que sejam aplicadas, aos fornecedores oportunistas, as sanções previstas na lei.

Palavras-chave: Pregão Eletrônico. Compras Públicas. Nova Economia Institucional.

\section{Abstract}

The research investigated the risk factors fortified by the use of the electronic bidding. As a theoretical foundation, the principles of the transaction costs' theory were used. An investigative and descriptive research has been performed, with quantitative approach, aiming to classify the Union supplier companies according to the risk degree presented to the supplying contracts. There have been elaborated constructs, and these have been validated through Cronbach's Alpha. Afterwards, factorial and cluster analysis were performed. Through these analyses it was possible to classify the suppliers into three groups. Through the results, it is assumed that the Government Agencies must create safeguards to be protected from opportunist actions. Therefore, it is important that there is a correct specification of the bidden products not to give access to the quotation of the lower quality products, and also, that the penalties fixed in law are applied to the opportunist suppliers, even if it implies in larger transaction costs.

Keywords: Electronic Bidding. Public Purchases. Theory of New Institutional Economy. 


\section{INTRODUÇÃo}

Com a introdução da tecnologia no processo administrativo, as organizações públicas passaram por profundas mudanças sociais, econômicas e políticas. Tais transformações requerem novos modelos de gerenciamento inovador, assim como novos instrumentos, procedimentos e formas de ação.

Esse processo veio implementando na maioria dos setores públicos uma política de responsabilidade social cada vez mais rigorosa. Aliado à perspectiva econômica do país vislumbra-se a necessidade, urgente e relevante, de se estudar várias possibilidades de otimizar a forma como o dinheiro público é gasto. (SANTANA; ROCHA, 2007)

Há um reconhecimento generalizado de que uma das estratégias mais importantes a ser adotada é a do desenvolvimento de ações voltadas ao estabelecimento de um governo adaptado às características e às necessidades de uma nova era do conhecimento, em que a adoção dessas novas tecnologias da informação $e$ comunicação (TIC) proporcionem melhorias nos processos de gestão interna e de prestação de serviços à sociedade. (COELHO, 2001)

Com o intuito de aliar essa necessidade de redução de gastos com o aumento na transparência $e$ responsabilidade na gestão de recursos públicos, foi instituído, no ano de 2002, o Pregão Eletrônico (leilão reverso) na Administração Pública brasileira, por meio do Decreto n. 10.520/2002. Porém, o Pregão Eletrônico é uma modalidade de compras ainda pouco explorada. Sendo assim é preciso investigar possíveis fatores que podem prejudicar os contratos firmados por meio dessa modalidade.

Alguns trabalhos foram realizados nesta área, como o de Menezes (2007) que propõe um modelo de licitação que não considera apenas o preço do produto, mas vários outros atributos como qualidade e prazo de garantia. Rezende et al. (2007) realizaram uma análise dos impactos trazidos pela modalidade de licitação por Pregão Eletrônico na eficácia dos contratos de serviço continuado da Administração Pública. Santana e Rocha (2007) propõem a aplicação da Teoria do custo total de propriedade e do Ciclo de vida do produto às licitações, para que não apenas o preço seja visado pelo gestor público, mas os custos após a aquisição do produto, como manutenção, gasto de energia. Silva e Ferreira (2007) propõem um modelo que utiliza o valor estimado para obter o valor da redução ou aumento dos preços trazido pelo Pregão Eletrônico, o que pode representar um equívoco, já que o gestor público não utiliza critérios na estimativa do valor da licitação.

Para alguns autores, a exemplo de Vasconcellos (2008), o pregão eletrônico é a modalidade de licitação que apresenta o maior conjunto de pontos positivos para a administração pública, dos quais, merecem destaque os melhores preços trazidos pelo aumento significativo no número de fornecedores.

Porém, segundo Rezende et al. (2007), fatores como assimetria de informação, custos de transação, oportunismo e racionalidade limitada, que podem tornar um contrato incompleto, estão presentes em todo o processo de licitação e podem afetar na eficácia dos contratos.

Sendo assim, as Organizações Públicas, ao realizar processos licitatórios através de Leilões Reversos, podem estar expostas a vários riscos em suas transações. Alguns autores a exemplo de Smeltzer e Karr (2003) e Carter et al. (2007) afirmam que o fato de apenas o menor preço ser levado em conta para a realização das transações, pode ocasionar falta de reputação e de frequência de transação entre o comprador e o vendedor, o que traz risco de ações oportunistas.

Em meio a essas organizações públicas expostas ao risco, encontram-se as universidades públicas que, assim como outras organizações, como escolas e hospitais, necessitam de agilidade em suas compras para conseguir atingir seus objetivos de prestar serviços em ensino, pesquisa e extensão.

Assim, investigar os fatores de riscos potencializados pela utilização do pregão eletrônico, dos quais se destacam o oportunismo, a especificidade dos ativos, a incerteza, a frequência e a racionalidade limitada, todos discorridos na Nova Economia Institucional (NEI), torna-se um esforço de pesquisa que pode gerar contribuições para gestores, compradores, fornecedores, etc. Para isolar a influência de outros fatores, tomou-se como referência o universo organizacional específico da Universidade Federal de Viçosa. 


\section{Referencial Teórico}

Neste capítulo serão tratados os principais pressupostos da Nova Economia Institucional (NEI), teoria escolhida para fundamentar os resultados desta pesquisa. Posteriormente, serão apresentadas as características dos agentes econômicos que foram utilizadas para subsidiar a criação dos constructos propostos por esta pesquisa.

\subsection{Nova Economia Institucional}

A Nova Economia Institucional (NEI) comporta em sua origem uma crítica a determinados pressupostos da ortodoxia neoclássica, particularmente em suas proposições de individualismo metodológico, de racionalidade ilimitada dos agentes econômicos e de existência de informação completa e homogeneamente acessível. (VALLE; FILHO, 2001)

Da somatória do livre acesso às informações consideradas relevantes, juntamente com uma capacidade ilimitada de processar todas essas informações, resultaria uma decisão precisa e coerente, que seria pautada pela maximização. Outro ponto divergente em relação à abordagem neoclássica deriva da não consideração, em seus modelos, da ocorrência de fricções, isto é, custos não vinculados à produção $e$ à distribuição, mas associados ao funcionamento do sistema. (WILLIAMSON, 1985)

Buscando a elaboração de uma abordagem mais próxima à realidade, os teóricos da NEI observaram que as instituições não poderiam ser negligenciadas no estudo do ambiente econômico, dada sua grande influência não apenas sobre os custos de seu funcionamento (custos de transação), mas também sobre a própria tecnologia. (NORTH, 1994)

Conforme afirma Zylbersztajn (1995), a economia de custos de transação (ECT) tem por objetivo estudar as características dos custos de transação como indutores de modos alternativos de organização da produção pelas firmas, ou seja, sua governança, dentro de um quadro de análise institucional.

A Economia de Custos de Transação ganhou força através dos estudos de Williamsom (1985). A ECT foi construída com base em alguns pressupostos. O pressuposto básico é a existência de custos nas transações em si. Ou seja, além do preço do produto ou serviço final, envolvem-se também os custos para transacionar esse produto ou serviço, levando-se em conta não apenas os custos gerados pelos contratos feitos via mercado, mas também os coordenados pelas firmas. (LUCCI, 2004)

Outro pressuposto concerne às características dos agentes econômicos. Os agentes têm racionalidade limitada e são capazes de comportamento oportunista. A especificidade dos ativos, unida à racionalidade limitada, ao oportunismo e à incerteza, causa tensão contratual e organizacional. Esse aspecto foi abordado por Williamson et al. (1990), que desenvolveram um modelo a partir da incorporação dos chamados "atributos das transações" e dos "pressupostos comportamentais" ao conceito de custos de transação. Em linhas gerais, afirma-se que tais custos decorrem desses dois condicionantes.

\subsubsection{Racionalidade Limitada}

Ao realizar um contrato, os indivíduos tentam se assegurar prevendo todos os cenários e eventualidades possíveis. No entanto, é impossível saber ao certo tudo o que pode acontecer. Para Júnior e Machado (2003), os agentes econômicos procuram agir racionalmente no momento em que tomam uma determinada decisão. No entanto, possuem uma limitação cognitiva que os impedem de antever algo que possa acontecer no futuro. A racionalidade limitada deriva da convicção de que os agentes econômicos, embora, eles tentem pautar suas ações em moldes estritamente racionais, só conseguem fazê-lo de modo parcial, devido à assimetria informacional e à restrita capacidade de processamento das informações. (VALLE; FILHO, 2001)

Segundo Martins (1999), a racionalidade limitada é um dos pressupostos basilares da ECT. Ao rejeitar o pressuposto de racionalidade plena, ela difere-se da teoria neoclássica. A impossibilidade de predizer todos os acontecimentos futuros que envolvem uma transação leva a delineamentos de contratos que, enfim, são necessariamente incompletos. As usuais salvaguardas nos contratos materializam esse reconhecimento, ao mesmo tempo em que se caracterizam como mecanismos amortecedores para o problema da incompletude dos contratos e suas consequências.

De acordo com Williamson (1985), ao longo das teorias econômicas se distinguem três níveis de 
racionalidade: uma forma forte, considerada a partir dos esforços de maximização, uma forma semiforte, caracterizada com a racionalidade limitada e a forma débil ou mais fraca, que se denomina de racionalidade orgânica. A racionalidade limitada caracteriza-se como uma forma semiforte de racionalidade, pois se supõe que os atores econômicos são intencionalmente racionais, mas, devido às suas limitações, apenas parte do conjunto de conhecimentos e informações consegue ser processado individualmente (ARBAGE, 2004). Ao assumir como verdadeiro, o pressuposto da racionalidade limitada do ser humano, a qualidade das informações passa verdadeiramente a ser uma variável-chave para a tomada de decisões, sendo esta, talvez, uma das grandes contribuições teóricas da nova economia institucional.

Portanto, se os agentes fossem plenamente racionais, seriam capazes de formular contratos completos com cláusulas representativas dos problemas ex-ante, reduzindo os problemas de adaptação, ou seja, custos de transação ex-post, diminuindo a necessidade de se criar formas sofisticadas de governança. (DINIZ et al., 2004)

\subsubsection{Oportunismo}

Oportunismo é o outro pressuposto comportamental, sendo um conceito que resulta da ação dos indivíduos na busca do seu autointeresse. Para Alves e Staduto (1999), por causa da oportunidade, o tomador de decisão pode, inescrupulosamente, procurar atender seus próprios interesses, e que há a dificuldade de conhecer a priori quem é de confiança e quem não é, podendo ser definido como problema de assimetria informacional. Williamson (1985, p. 76) definiu oportunismo como "[...] procurar seus próprios interesses com avidez [...]", incluindo comportamentos como mentira e trapaça, tão bem como as mais sutis formas de enganar, tal como violação de contrato. Depreende-se, pois, que o oportunismo está vinculado à noção de que os agentes econômicos buscarão sempre obter o maior ganho possível no decorrer das transações, ainda que isto implique perdas aos demais. (VALLE et al., 2002)

O comportamento oportunista pode ocorrer tanto antes da efetivação dos acordos, conhecido como oportunismo ex-ante, quanto após a execução dos mesmos, denominado oportunismo ex-post. Nesse sentido, os custos de transação ex-ante referem-se a dispêndios para negociar os termos do contrato e estabelecer salvaguardas, ou seja, são custos preventivos. (LAUREANO, 2005)

Diante disso, ambos os pressupostos, racionalidade e oportunismo, indicam um mesmo sentido de fundamentação teórica: a impossibilidade de confecção de contratos completos. Esta máxima resulta na necessidade de contínuas negociações pós-transação que terminam por tornar a questão da flexibilidade como um elemento importante a ser considerado quando da confecção das estruturas de governança nos arranjos interorganizacionais. Os agentes econômicos, devido ao oportunismo e a racionalidade limitada intrínseca aos indivíduos, desenvolvem estruturas de governança para reduzir os custos envolvidos em uma determinada transação, além de garantir a continuidade do contrato e a redução dos custos de transação, de forma que ações oportunistas sejam afastadas. (JÚNIOR; MACHADO, 2003)

Não se pode afirmar, no entanto, que todos os agentes agem de forma oportunista o tempo todo, mas não se pode ignorar que estes venham a agir oportunisticamente em algum momento, com a finalidade de buscar apropriar-se das quase-rendas advindas da existência de ativos específicos.

Existem, segundo Zylbersztajn (2000), três razões explicativas que fazem com que os agentes não quebrem os contratos, mesmo quando tentados pela existência dessas quase-rendas: a reputação, as garantias legais e os princípios éticos.

No que diz respeito à reputação, o indivíduo não rompe o contrato, em situação oportunística, por saber que se o fizer, terá interrompido o fluxo de renda futura. No caso das garantias legais, os agentes econômicos terão um desestímulo para a quebra contratual oportunística, pelo fato de existir mecanismos punitivos instituídos pela sociedade, através da legislação associada a um sistema capaz de identificar, julgar e punir os agentes que rompem os contratos. Quanto aos princípios éticos, eles devem ser entendidos como uma construção humana que tem como uma de suas finalidades a restrição ao comportamento oportunista. É uma restrição informal que disciplina o comportamento daqueles que exercem o jogo social. (DINIZ, 2004) 


\subsubsection{Frequência}

A frequência é uma medida da recorrência com que uma transação se efetiva. Seu papel é duplo. Primeiro, quanto maior a frequência, menores serão os custos fixos médios associados à coleta de informações e à elaboração de um contrato complexo que imponha restrições ao comportamento oportunista. Segundo, se a frequência for muito elevada, os agentes terão motivos para não impor perdas aos seus parceiros, na medida em que uma atitude oportunista poderia implicar a interrupção da transação $e$ a consequente perda dos ganhos futuros derivados da troca. (SOUZA et al., 1998)

Para Martins (1999), à medida que o número de transações tende a ser contínuo entre agentes, torna-se viável, em termos de custo, a adoção de estruturas de governança que permitam o levantamento de informações, a confecção de contrato e o monitoramento de seu cumprimento. A teoria aponta que uma maior frequência nas transações entre os mesmos agentes gera o que se chama de "reputação".

O detalhe é que a reputação tende a reduzir os custos de transação tendo em vista não haver a necessidade de se buscar informações acerca do parceiro comercial e da qualidade do produto transacionado. Portanto, segundo a ECT, quanto maior a frequência nas transações, maior o nível de reputação e consequentemente menores os custos de transação envolvidos. (ARBAGE, 2004)

A partir do momento em que as partes repetem uma transação, há uma redução de incerteza quanto ao não cumprimento do contrato. A frequência das transações reduz os custos "ex ante". Aumentando a frequência, os custos de transação tendem a baixar. (JÚNIOR; MACHADO, 2003)

Assim, segundo a ECT, ao se relacionar níveis de investimentos específicos com padrões de frequência nas transações pode-se estabelecer uma estrutura de governança que minimize os custos de transação. Por outro lado, há que se levar em conta que toda estrutura de governança apresenta custos relacionados à sua construção e manutenção. (ALVES; STADUTO, 1999)

\subsubsection{Incerteza}

Segundo Santos (2001), a incerteza consiste na incapacidade dos agentes de prever e estabelecer cláusulas que assegurem a performance dos agentes quando há ocorrência de eventos não previsíveis. Ou seja, a incerteza não é redutível ao risco. Quanto mais incerto é o ambiente, mais ineficientes serão as adaptações descentralizadas, gerando, portanto, maior instabilidade para as transações.

A incerteza é a terceira característica das transações e está associada à impossibilidade de os agentes preverem algo que possa acontecer e colocar em risco a transação como, por exemplo, as variações climáticas. Essa situação faz com que haja um prazo maior para que as partes renegociem um novo contrato. (JÚNIOR; MACHADO, 2003)

A partir do momento em que as transações entre os agentes se intensificam, as partes envolvidas começam a confiar nas atitudes umas das outras, levando à redução da incerteza. "O grau de incerteza envolvido em uma determinada transação está relacionado à confiança que os agentes possuem em sua capacidade de antecipar os eventos futuros". (HIRATUKA, 1997, p. 19)

No campo organizacional, a fonte fundamental de incerteza decorre exatamente do suposto de racionalidade limitada dos agentes. Não fosse esse aspecto, as estruturas de governança seriam capazes de se ajustar às alterações havidas no ambiente. Para muitos autores, esse é o grande problema das organizações econômicas: a constante necessidade de adaptação às alterações de natureza institucional que ocorrem no ambiente dos negócios. (ARBAGE, 2004)

Há, porém, uma segunda fonte de incerteza e que também se relaciona com aspectos comportamentais: o oportunismo. Adicionalmente, as incertezas quanto ao futuro e à busca com avidez da realização do autointeresse fazem com que, em algum momento, seja possível comportamentos oportunistas por parte dos agentes. (MARTINS, 1999)

A aceitação do pressuposto de que os agentes podem se comportar de forma oportunista insere um componente de incerteza nas relações comerciais na medida em que não há como prever exatamente o comportamento dos agentes mesmo após a confecção de contratos. (ARBAGE, 2004)

Do conjunto de restrições e dos condicionantes indicados pela teoria, surgem incertezas e riscos nas transações. O risco é um elemento que pode ser calculado e estabelecido seu grau de probabilidade 
de ocorrência, de forma que pode ser inserido nos custos tradicionais de produção (ARBAGE, 2004). Desse modo, o risco passa a ser considerado como um elemento não gerador de custo de transação tendo em vista a possibilidade de cálculo probabilístico e a sua inclusão nas planilhas de custos tradicionais. A incerteza, por outro lado, é um evento não previsto $e$, portanto, não pode ser mensurado. A incerteza passa então a ser considerada como uma real fonte de custo de transação. (ARBAGE, 2004)

\subsubsection{Especificidade dos Ativos}

A especificidade dos ativos é introduzida por Williamson (1985) para designar a perda de valor dos investimentos no caso de quebras oportunísticas dos contratos (ZYLBERSZTAJN, 2002). Um ativo é especifico quando a sua realocação para outra atividade, no caso de um rompimento no contrato, por exemplo, é praticamente inexistente. A especificidade de ativos coloca em risco o investimento feito, caso a transação não seja realizada pelo fato de o uso alternativo desse investimento ser baixo ou não existir (JÚNIOR; MACHADO, 2003). Segundo Souza et al. (1998), ativos são específicos se o retorno associado a eles depende da continuidade de uma transação específica. Quanto maior a especificidade dos ativos, maior a perda associada a uma ação oportunista por parte de outro agente, e, consequentemente, maiores serão os custos de transação.

Com a presença de especificidade dos ativos, os agentes envolvidos na transação passam a ter um relacionamento semelhante ao de um monopólio bilateral, no qual ambas as partes possuem um determinado poder de barganha e se utilizam desse poder, a fim de buscar para si uma maior participação na "renda" gerada por esse ativo específico. (PINTO JÚNIOR; PIRES, 2000)

No entanto, o rompimento do contrato pode não ser interessante quando a alta especificidade está muito mais definida para uma das partes. Nesse caso, a parte mais afetada se salvaguardará de uma eventual ruptura contratual pela parte não afetada. Outra situação acontece quando todos os envolvidos fizerem investimentos específicos, ou seja, no caso de dependência bilateral. Assim acontecendo, os esforços serão concentrados para que o contrato continue indefinidamente. (DINIZ et al., 2004)

\section{Metodologia}

Para a classificação da pesquisa, tomou-se como base o critério proposto por Vergara (2005) que a caracteriza em relação a dois aspectos básicos: quanto aos fins e quanto aos meios.

Quanto aos fins, trata-se de pesquisa descritiva em função do objetivo de identificar, descrever e classificar o perfil das empresas fornecedoras da Universidade Federal de Viçosa. Segundo Gil (2002), as pesquisas descritivas são aquelas que têm como objetivo primordial a descrição das características de determinada população ou fenômeno, ou, então, o estabelecimento de relações entre as variáveis.

Este trabalho, quanto aos meios de investigação, recorreu a técnicas de pesquisa bibliográfica, documental e pesquisa de campo com o uso de questionário como instrumento de coleta de dados.

Bibliográfica, porque recorreu a um material acessível ao público em geral, como livros, artigos, teses e dissertações para realizar a investigação sobre os assuntos relacionados ao tema de pesquisa.

A investigação foi também documental, pois foram utilizados documentos eletrônicos da UFV, como Atas dos Pregões, Processos de Licitação e outros documentos pertinentes com o objeto do estudo.

Foi também utilizado um questionário que foi aplicado junto a todas as empresas que retiraram edital de licitações de janeiro a outubro de 2009.

\subsection{Estratégia de Coleta de Dados}

Para o levantamento de dados, foram postados 1.900 formulários eletrônicos no site www.quantweb. com.br e convite remetido aos proprietários-dirigentes das empresas que retiraram edital de licitação no ano de 2009 na Universidade Federal de Viçosa. Foram obtidos 298 formulários válidos, tendo um retorno aproximado de $15,7 \%$.

Na estratégia de coleta de dados utilizou-se amostra aleatória, estatisticamente significativa, de acordo com a Equação 1, sugerida por Triola (2005):

$$
\eta=\frac{\sigma^{2} \cdot p \cdot q \cdot N}{e^{2} \cdot(N-1)+\sigma^{2} \cdot p \cdot q}
$$


em que,

$\eta=$ tamanho da amostra;

$\sigma=$ nível de confiança escolhido, expresso em números de desvios-padrão;

$p=$ probabilidade de escolher aleatoriamente uma empresa em que se observe a ocorrência do fenômeno;

$q=(1-p)$, ou seja, probabilidade de não observação do fenômeno;

$N=$ tamanho total da população; $e$

$e=$ erro máximo permitido.

Considerando $p$ e $e=0,5$, o número de fornecedores, cadastrados na União no ano de 2009, $N=$ $214.000, \sigma=1,96$ (95\%), pode-se verificar que o erro máximo associado foi de $5,8 \%$.

O questionário utilizado foi composto por perguntas correspondentes as características da empresa e algumas questões do tipo escala Likert para a elaboração de constructos de acordo com os princípios da ECT, com exceção da racionalidade limitada, onde foram feitas questões de concordância (discordo ou concordo) simulando testes do tipo verdadeiro ou falso, com o objetivo de mensurar o conhecimento dos entrevistados em relação à modalidade de licitação por Pregão Eletrônico.

O escopo diversificado do trabalho pode ser confirmado pela Tabela 1 que descreve a participação de 15 diferentes estados.

Tabela 1: Composição da amostra de acordo com os estados

\begin{tabular}{|l|l|l|l|}
\hline \multicolumn{1}{|c|}{ RANKing } & \multicolumn{1}{c|}{ Estado } & \multicolumn{1}{c|}{ Empresas } & \multicolumn{1}{c|}{ Percentual } \\
\hline 1 & Minas Gerais & 113 & 37,9 \\
\hline 2 & São Paulo & 83 & 27,9 \\
\hline 3 & Paraná & 26 & 8,7 \\
\hline 4 & Rio de Janeiro & 23 & 7,7 \\
\hline 5 & Rio Grande do Sul & 13 & 4,4 \\
\hline 6 & Santa Catarina & 12 & 4,0 \\
\hline 6 & Distrito Federal & 12 & 4,0 \\
\hline 8 & Goiás & 6 & 2,0 \\
\hline 9 & Mato Grosso do Sul & 3 & 1,0 \\
\hline 10 & Espírito Santo & 2 & 0,7 \\
\hline 11 & Bahia & 1 & 0,3 \\
\hline
\end{tabular}

\begin{tabular}{|l|l|l|l|}
\hline 11 & Ceará & 1 & 0,3 \\
\hline 11 & Pará & 1 & 0,3 \\
\hline 11 & Pernambuco & 1 & 0,3 \\
\hline 11 & Sergipe & 1 & 0,3 \\
\hline & Total & 298 & 100,0 \\
\hline
\end{tabular}

Fonte: Dados da Pesquisa

Foram realizadas análises multivariadas utilizando o software Statistical Package for the Social Science (SPSS) versão 15.0, licenciada. Vários artigos têm utilizado esse tipo em pesquisas na Administração Pública a exemplo de Houston (2000), Houston (2005) e Fernandez et al. (2008) que levantaram características dos servidores públicos como motivação e liderança, Rosenberg e Turvey (2008) que avaliou políticas agrícolas, Martin (2004) e Modrego-Rico (2005), que analisaram agências de transferência de tecnologia, Zerbinati e Souitaris (2005) e Xiaoqing (2007), que utilizaram a análise multivariada no planejamento público e Agus et al. (2007) e Taylor (2007) que mediram a qualidade dos serviços públicos prestados.

Em seguida, far-se-á uma breve descrição das análises fatorial e de cluster, contextualizando sua importância no estudo em questão.

\subsubsection{Análise Fatorial}

Após a eliminação de respondentes outliers e dos questionários inconsistentes, através de uma análise descritiva dos dados, efetuou-se a análise fatorial para confirmar se a divisão realizada seria confirmada. Segundo Hair et al. (2005), em termos gerais, a análise fatorial aborda o problema de analisar estruturas das inter-relações entre grande número de variáveis, definindo um conjunto de dimensões latentes comuns, denominado "fator". Para o cálculo dos fatores, foi utilizado o procedimento dos componentes principais, por ser o método mais adequado, quando a preocupação principal é a previsão ou a obtenção de número mínimo de fatores necessários, para explicar a máxima variância representada pelo conjunto original das variáveis.

Segundo Ferreira e Braga (2007), a análise fatorial segue o seguinte conjunto de procedimentos estatísticos: 
a) determinação das correlações entre todas as variáveis;

b) extração de fatores significativos e necessários à representação dos dados;

c) transformação dos fatores, por intermédio do procedimento de rotação, como forma de torná-los inteligíveis; $e$

d) construção dos escores fatoriais.

Na determinação das correlações, é possível excluir aquelas variáveis que não admitem relações com as demais. A segunda etapa consiste na ponderação e na seleção do número de fatores necessários à explicação do conjunto de dados, bem como do método de cálculo para sua obtenção. O procedimento mais comum tem sido a utilização dos componentes principais para o cálculo dos fatores. Na terceira etapa, rotação dos componentes principais, é comum a utilização do método VARIMAX, a fim de minimizar o número de variáveis altamente relacionadas com cada um dos fatores, facilitando a interpretação dos resultados. A quarta etapa consiste na obtenção dos escores fatoriais para cada unidade presente na amostra. $\mathrm{O}$ escore fatorial é resultante da multiplicação do valor padronizado da variável i pelo coeficiente do escore fatorial correspondente. $\mathrm{O}$ j-ésimo fator, $\mathrm{Fj}$, pode ser obtido, empregando-se a Equação (1), adaptada de Manly (1986),

$$
F_{j}=\sum_{i=1}^{p} W_{j i} X_{I}=W_{j 1} X_{1}+W_{j 2} X_{2}+\ldots+W_{j p} X_{p}
$$

em que, os Wji são os coeficientes dos escores fatorais; e p é o número de variáveis.

\subsubsection{Análise de Cluster}

Conforme Everitt (1993), a análise de cluster é uma técnica estatística que objetiva agrupar os indivíduos (casos) que possuem características semelhantes em função de um conjunto de variáveis selecionadas. Assim, a análise de cluster classifica os indivíduos (casos) em grupos homogêneos, denominados clusters ou conglomerados. Entende-se, portanto, que os grupos criados pela análise de cluster são semelhantes entre si (dentro do cluster a variância é mínima) e diferentes de outros clusters (entre clusters a variância é máxima). Entende-se, portanto, que é possível segmentar os for- necedores da União em função das suas características descritas pela ECT, elucidando assim o grau de risco de cada grupo.

Neste trabalho foi utilizado o método hierárquico aglomerativo de Ward. Segundo Ferreira e Braga (2007), seu procedimento básico consiste em computar uma matriz de distância ou similaridade entre os indivíduos, a partir da qual se inicia um processo de suas sucessivas fusões, com base na proximidade ou similaridade entre eles. Essa matriz é simétrica, com zeros na diagonal principal, e é obtida mediante vários métodos. Um dos mais comuns consiste no emprego do quadrado da distância euclidiana como medida de semelhança entre as observações, expressa matematicamente por:

$$
d_{(A, B)}=\left[\sum_{i=1}^{0}\left(X_{i(A)}-X_{i(B)}\right)^{2}\right]^{1 / 2}
$$

Onde:

$d_{(\mathrm{A}, \mathrm{B})}=$ a medida de distância euclidiana da observação A a B;

$\mathrm{i}=$ indexador das variáveis.

Se a distância euclidiana for próxima a zero, significa que os objetos comparados são similares.

\section{Resultados e Discussão}

Para a análise da confiabilidade dos constructos utilizados nesta pesquisa, foi calculado o Alfa de Cronbach de cada categoria correspondente a um princípio da ECT. De acordo com Hair et al. (2005), ele é capaz de revelar o grau em que os itens de um instrumento são homogêneos e refletem um determinado constructo implícito. O coeficiente Alfa de Cronbach varia entre 0,00 e 1,00, sendo os valores de 0,60 a 0,70 considerados o limite inferior de aceitabilidade.

Após a análise dos resultados verifica-se, na Tabela 2, que os valores estão acima do limite inferior de aceitabilidade, o que evidencia a existência de confiabilidade na mensuração dos princípios estabelecidos. Não foi calculado o Alfa de Cronbach para o principio de racionalidade limitada, pois ele constou de uma mensuração do grau de racionalidade de cada respondente, sendo impossível a realização do cálculo. 
Tabela 2: Teste do Alfa de Cronbach para categorias consideradas na pesquisa

\begin{tabular}{|l|c|c|}
\hline \multicolumn{1}{|c|}{ Categoria } & $\begin{array}{c}\text { Grupo de } \\
\text { Perguntas }\end{array}$ & Alfa de Cronbach \\
\hline $\begin{array}{l}\text { Especificidade } \\
\text { dos Ativos }\end{array}$ & $1-4$ & 0,732 \\
\hline Oportunismo & $5-9$ & 0,752 \\
\hline Incerteza & $10-13$ & 0,717 \\
\hline Frequência & $14-17$ & 0,704 \\
\hline
\end{tabular}

Fonte: Dados da Pesquisa

Para maior confiabilidade dos resultados foi utilizada a análise fatorial para a extração de fatores. Esse procedimento poderia ser dispensável já que os constructos se basearam na Economia dos Custos de Transação, que foram validados pelo Alfa de Cronbach, porém, caso os fatores extraídos por esse teste representem os princípios construídos, eles colaborarão com a validação dos resultados.

As variáveis utilizadas apresentaram significativo ajustamento representado pelo resultado do teste de KMO (Kaiser-Meyer-Olkin) de 0,692 e pelo teste de Bartlett, significativo, acima de $0,1 \%$ de probabilidade.

A análise fatorial resultou na extração de cinco fatores com raiz característica (eigenvalues) maiores que 1 (um) que respondem, em conjunto, por $60,52 \%$ da variância total dos dados, conforme a Tabela 3. Segundo Hair et al. (2005), em Ciências Sociais, cujas informações geralmente são menos precisas, uma solução que explique $60 \%$ da variância total e, em alguns casos, até menos, é considerada satisfatória.

Tabela 3: Variáveis utilizadas na análise fatorial

\begin{tabular}{|c|c|c|c|}
\hline FATOR & $\begin{array}{c}\text { Raiz Carac- } \\
\text { Terística }\end{array}$ & $\begin{array}{l}\text { VARIÂNCIA EXPLICA- } \\
\text { DA PELO FATOR (\%) }\end{array}$ & $\begin{array}{c}\text { VARIÂNCIA } \\
\text { ACUMULADA } \\
(\%)\end{array}$ \\
\hline 1 & 2,984 & 17,554 & 17,554 \\
\hline 2 & 2,427 & 14,275 & 31,829 \\
\hline 3 & 1,911 & 11,239 & 43,068 \\
\hline 4 & 1,824 & 10,730 & 53,798 \\
\hline 5 & 1,142 & 6,719 & 60,516 \\
\hline
\end{tabular}

Fonte: Dados da Pesquisa
Em função da análise das cargas fatoriais correspondentes aos coeficientes de correlação entre a variável i e o fator $j$, após rotação ortogonal pelo método Varimax, foi possível classificar cinco fatores e defini-los de acordo com a sua representação homogênea, conforme ilustra a Tabela 4.

Colaborando com a construção proposta, os fatores foram exatamente iguais aos testados anteriormente, o que valida o constructo dos escores.

\subsection{Fator 1 - Oportunismo}

Essa variável busca mensurar se, em contrapartida às vantagens econômicas trazidas pelo Pregão Eletrônico, podem existir perdas na qualidade dos produtos comprados por causa do oportunismo contido nas estratégias dos agentes.

Para Azevedo (2000), cientes da incompletude dos contratos, os agentes constroem estruturas de governança para lidar com as lacunas inevitavelmente presentes em contratos internos e externos às organizações. Por isso, ao elaborar um edital, os órgãos públicos devem se certificar de que a especificação do produto descreve fielmente aquilo que ela deseja, pois, caso o contrário, os licitantes irão se aproveitar dessa incompletude para cotar produtos de pior qualidade ou que não atendam às necessidades.

Colaborando com essa afirmação, a média de concordância para esse fator é alta, significando que a maioria das instituições analisadas age com oportunismo diante de editais com especificações incompletas.

Isso comprova as afirmações de Carter et al. (2004) e Jap (2003), quando sugerem que embora os leilões inversos conduzam a preços diminuídos para compradores, eles também podem resultar em maiores ações oportunistas por parte dos vendedores. Para Gattiker et al. (2005), embora se pense que leilóes reversos poderiam diminuir suspeitas de oportunismo devido à transparência, ele afeta a relação comprador-vendedor e, assim, o nível de confiança entre eles.

\subsection{Fator 2 - Especificidade dos Ativos}

Esse fator está ligado ao princípio da especificidade dos ativos e todas as variáveis que o compõem são uma forma de avaliar se o bem é muito ofertado no mercado ou é oferecido por um número reduzido 
Tabela 4: Matriz fatorial após rotação ortogonal VARIMAX

\begin{tabular}{|c|c|c|c|c|c|}
\hline \multirow[t]{2}{*}{ VARIÁVEIS } & \multicolumn{5}{|c|}{ COMPONENTES ROTACIONADOS } \\
\hline & FATOR 1 & FATOR 2 & FATOR 3 & FATOR 4 & FAtOR 5 \\
\hline Intensidade de concorrência & & 0,806 & & & \\
\hline Poucos fabricantes do produto vendido & & 0,782 & & & \\
\hline Ocorrência de licitações desertas & & 0,596 & & & \\
\hline $\begin{array}{l}\text { Pequeno número de participantes } \\
\text { em Pregões Eletrônicos }\end{array}$ & & 0,786 & & & \\
\hline Cotação de produtos de má qualidade & 0,719 & & & & \\
\hline $\begin{array}{l}\text { Oportunismo em editais com } \\
\text { especificações incompletas }\end{array}$ & 0,770 & & & & \\
\hline Cotação de produtos fora das especificações do edital & 0,755 & & & & \\
\hline $\begin{array}{l}\text { Oportunismo em regiões distantes } \\
\text { para compensar custos }\end{array}$ & 0,755 & & & & \\
\hline $\begin{array}{l}\text { Ocorrência de descumprimento de contrato } \\
\text { por problemas na contratação de frete }\end{array}$ & & & 0,816 & & \\
\hline $\begin{array}{l}\text { Ocorrência de descumprimento de contrato por } \\
\text { problemas com tempestades, acidentes, dentre outros }\end{array}$ & & & 0,704 & & \\
\hline $\begin{array}{l}\text { Ocorrências de descumprimento de contrato } \\
\text { por que fornecedores não conseguiram } \\
\text { honrar com o fornecimento }\end{array}$ & & & 0,719 & & \\
\hline $\begin{array}{l}\text { Ocorrências de descumprimento de contrato } \\
\text { por causa de fatores macroeconômicos }\end{array}$ & & & 0,661 & & \\
\hline $\begin{array}{l}\text { Políticas de preços mais favoráveis a } \\
\text { Órgãos Públicos conhecidos }\end{array}$ & & & & 0,784 & \\
\hline $\begin{array}{l}\text { Políticas de qualidade mais favoráveis } \\
\text { a Órgãos Públicos conhecidos }\end{array}$ & & & & 0,769 & \\
\hline $\begin{array}{l}\text { Esforço para vencer disputas de } \\
\text { Órgãos Públicos conhecidos }\end{array}$ & & & & 0,779 & \\
\hline Esforço para cumprimento das normas & & & & 0,511 & \\
\hline Escore de Racionalidade & & & & & 0,695 \\
\hline
\end{tabular}

Fonte: Dados da Pesquisa

de empresas. Segundo Balestrin e Arbage (2007), a questão da especificidade dos ativos é um dos pontos importantes da ECT e fonte de atritos. O ponto-chave destacado é a maior ou menor possibilidade de utilização alternativa de um ativo relacionado aos custos envolvidos em um processo de produção. Quanto maior a especificidade de um ativo, menor tende a ser a possibilidade de utilização alternativa do mesmo. As partes de uma transação podem exigir investimentos de propósitos gerais ou específicos. As transações que exigem investimentos específicos implicam custos de transação maiores devido exatamente ao fato de que a reutilização dos ativos não ocorre de forma automática e sem perdas.

Sendo assim, esse fator pode trazer risco aos contratos, pois, quando a licitação for para compra de ativos muito específicos, em que poucas ou apenas uma empresa participe, o preço dos produtos poderá ser cotado acima do valor de mercado ou a instituição poderá ficar sem o produto caso a vencedora não cumpra o contrato e não tenha outra empresa 
na concorrência acarretando, assim, prejuízos para as suas atividades.

\subsection{Fator 3 - Incerteza}

Todos os agentes econômicos estão sujeitos a eventos incertos, mesmo eles sendo de difícil previsão. Os órgãos públicos que realizam licitação também estão submetidos à incerteza, pois o fornecimento de produtos para eles não ocorre, na maioria das vezes, de maneira continuada, podendo, também, ser realizado por qualquer empresa do país, uma vez que estão sujeitos à legislação e não podem escolher qual empresa contratar.

Sob essa condição, os órgãos públicos estão expostos à ocorrência de eventos incertos, embora eles não se caracterizem como riscos previsíveis em seus contratos. Segundo Arbage (2004), o risco é um elemento não gerador de custo de transação tendo em vista a possibilidade de cálculo probabilístico. Já a incerteza, por outro lado, é um evento não previsto e, portanto, não pode ser mensurado.

\subsection{Fator 4 - Frequência}

Embora a frequência seja favorável aos Órgãos Públicos, já que, segundo Valle et al. (2002), transações mais recorrentes tendem a criar relações de confiança, desestimulando a emergência de práticas oportunistas, eles não podem criar estratégias para a construção dessas relações, devido às restrições impostas pela lei de licitações. Sendo assim, cabe a outra parte das transações, os fornecedores, criarem políticas para a construção dessas relações.

Ao analisar esse fator, observa-se que a média de concordância para ele é alta, o que pode ser favorável ao órgão público estudado, desde que esses fornecedores o considerem um órgão interessante para ter uma frequência de transações maior.

Os resultados contrariam o que foi dito por Beall et al. (2003), Loesch e Lambert (2007) e Smeltzer e Karr (2003), quando eles afirmaram que leilões reversos são contraditórios aos benefícios a longo prazo associados com "alianças de comprador-vendedor", já que o órgão comprador não escolhe o seu fornecedor, pois ganha aquele que tem o menor preço em detri- mento daquele que possui outras características como qualidade e entrega. Porém, ao analisar as estratégias dos fornecedores, é possível que essas empresas objetivam construir relações de longo prazo, por meio de políticas de preços mais favoráveis aos órgãos públicos parceiros.

É importante ressaltar que para a construção dos grupos através da análise de cluster, a escala desses fatores foi invertida para que a direção dos dados se torne igual para todos os escores.

\subsection{Fator 5 - Racionalidade Limitada}

O risco contido nesse fator é pautado na preocupação com a existência de assimetria informacional entre os fornecedores e os profissionais responsáveis pela execução dos processos licitatórios. Segundo Valle et al. (2002), a assimetria informacional estimula o aparecimento de práticas oportunistas, à medida que um determinado agente, dispondo de alguma informação, pode tentar se aproveitar disso como forma de elevar seus ganhos.

Sendo assim, quão maior for o nível de conhecimento do agente quanto à legislação, maior o risco de ocorrer uma ação oportunista devido à incompletude existente na lei; por isso, para efeito deste trabalho, quanto maior a racionalidade do agente, maior risco ele trará aos contratos firmados com a administração pública.

\subsection{Análise dos Grupos}

A análise de agrupamento, para complementação da análise fatorial, resultou grupos diferenciados de fornecedores. Utilizando o método de Ward foi possível dividir os fatores em três grupos distintos: 1 - baixo risco, alto risco e risco moderado. Na Tabela 5, pode-se observar as estatísticas descritivas dos fatores e é possível perceber as similaridades e as diferenças entre os grupos. É importante ressaltar que para a construção dos grupos através da análise de cluster, a escala do fator frequência foi invertida para que a direção dos dados se tornassem iguais para todos os fatores. Sendo assim, uma menor média na Tabela 5 significa maior busca pela frequência nas transações. 
Tabela 5: Estatística descritiva dos grupos

\begin{tabular}{|c|c|c|c|c|c|}
\hline GruPOS & FATORES & Mínimo & Máxıмо & MÉDIA & DESVIO-PADRÃO \\
\hline \multirow{5}{*}{ Baixo Risco } & Especificidade dos Ativos & 4 & 19 & 8,09 & 3,64 \\
\hline & Oportunismo & 4 & 24 & 11,67 & 4,37 \\
\hline & Incerteza & 4 & 20 & 9,91 & 4,88 \\
\hline & Frequência & 4 & 19 & 10,89 & 4,03 \\
\hline & Racionalidade Limitada & 6 & 21 & 13,96 & 3,46 \\
\hline \multirow{5}{*}{ Alto Risco } & Especificidade dos Ativos & 4 & 24 & 9,48 & 5,06 \\
\hline & Oportunismo & 4 & 24 & 18,27 & 4,52 \\
\hline & Incerteza & 12 & 24 & 18,26 & 3,15 \\
\hline & Frequência & 8 & 24 & 18,64 & 3,57 \\
\hline & Racionalidade Limitada & 7 & 24 & 14,94 & 3,41 \\
\hline \multirow{5}{*}{ Risco Moderado } & Especificidade dos Ativos & 4 & 22 & 8,34 & 4,27 \\
\hline & Oportunismo & 4 & 24 & 17,42 & 4,66 \\
\hline & Incerteza & 4 & 14 & 8,70 & 2,99 \\
\hline & Frequência & 11 & 24 & 19,29 & 3,50 \\
\hline & Racionalidade Limitada & 4 & 23 & 14,01 & 3,66 \\
\hline
\end{tabular}

Fonte: Dados da Pesquisa

Para complementar este estudo, foram propostas outras questões relativas às características das empresas fornecedoras da Universidade Federal de Viçosa. A Tabela 6 exibe as estatísticas descritivas dessas questões.

Tabela 6: Estatísticas descritivas

\begin{tabular}{|c|c|c|c|c|c|}
\hline VARIÁVEIS & GRUPO & Mínimo & Máxıмo & MÉdia & Desvio-PADRÃo \\
\hline \multirow{3}{*}{ Tempo de existência da empresa (em anos) } & Baixo Risco & 0,75 & 55 & 12,76 & 13,34 \\
\hline & Alto Risco & 0,5 & 80 & 10,19 & 10,89 \\
\hline & Risco Moderado & 0,5 & 44 & 10,80 & 9,47 \\
\hline \multirow{3}{*}{ Faturamento anual estimado (em mil) } & Baixo Risco & 50 & 2.000 .000 & $37.390,91$ & $211.694,72$ \\
\hline & Alto Risco & 50 & 900.000 & $27.027,98$ & $130.227,97$ \\
\hline & Risco Moderado & 10 & 500.000 & $11.205,44$ & $53.059,44$ \\
\hline \multirow{3}{*}{$\begin{array}{l}\text { Participação das licitações } \\
\text { no faturamento (\%) }\end{array}$} & Baixo Risco & 0 & 100 & 54,25 & 34,15 \\
\hline & Alto Risco & 2 & 100 & 62,10 & 33,03 \\
\hline & Risco Moderado & 0 & 100 & 47,27 & 32,75 \\
\hline \multirow{3}{*}{ Percentual de disputas vencidas (\%) } & Baixo Risco & 0 & 100 & 35,45 & 28,89 \\
\hline & Alto Risco & 0 & 90 & 33,61 & 23,68 \\
\hline & Risco Moderado & 0 & 100 & 32,69 & 25,58 \\
\hline
\end{tabular}

Fonte: Dados da Pesquisa 


\subsubsection{Grupo 1 - Baixo Risco}

Este grupo é formado por $17,79 \%$ das empresas licitantes, constituindo o menor grupo em comparação com os outros. Possui as menores médias nos fatores: especificidade dos ativos, oportunismo, frequência e racionalidade limitada. Sendo o grupo que apresenta menores riscos aos contratos da UFV.

O fato de ter baixa especificidade dos ativos traz maior segurança aos contratos, já que caso a empresa não cumpra as cláusulas estabelecidas outras empresas estarão aptas a realizar o fornecimento. Isso diminui substancialmente os custos de transação e a maior concorrência contribui para a diminuição do preço contratado.

Baixo oportunismo significa potencialidade para maior qualidade nas compras públicas e a maior chance de que o produto comprado será exatamente igual ao que foi pedido. Sendo assim, ao formalizar contratos com as empresas desse grupo, os custos atribuídos a recursos contra empresas e devoluções de mercadoria terão uma diminuição substancial.

Essas empresas também apresentam uma busca maior por frequência nas transações, o que representa políticas de melhores preços e qualidades para órgãos já conhecidos, o que privilegia uma continuidade no fornecimento e, assim, diminui a chance de atitudes oportunistas por parte dos agentes.

Quanto às características descritas na Tabela 6, essas empresas têm maior tempo de existência, sendo empresas melhores consolidadas no mercado o que representa uma vantagem em transações. São empresas com faturamento médio maior, o que representa que são empresas maiores e consequentemente mais organizadas do que as empresas do grupo 2. Outra característica favorável a essas empresas é um percentual de vitórias em licitações maior do que os demais grupos; o que significa que mesmo mantendo uma atitude ética, elas conseguem ter uma política de preços mais eficiente do que os demais grupos.

\subsubsection{Grupo 2 - Alto Risco}

Este grupo é formado por $50 \%$ das empresas fornecedoras da UFV, constituindo o maior grupo quando comparado com os outros. Ele possui as maiores médias nos fatores: especificidade dos ativos, oportunismo, incerteza e racionalidade limitada. Por isso, ele se configura como o grupo de empresas que mais apresentam riscos aos contratos da instituição.

Essas empresas possuem maior especificidade dos ativos, o que pode ser prejudicial, pois, caso elas não cumpram o contrato estabelecido, a substituição do fornecimento pode ficar comprometida pelo fato de não existirem outras empresas capazes de fornecer esses produtos. Segundo Williamson (1985), a especificidade de ativos coloca em risco o investimento feito, caso a transação não seja realizada pelo fato de o uso alternativo desse investimento ser baixo ou não existir.

Outro ponto negativo dessas empresas é o fato de elas terem as maiores médias do fator oportunismo, o que pode prejudicar a qualidade dos produtos comprados e a continuidade dos contratos firmados. $\mathrm{O}$ oportunismo se vincula à noção de que os agentes econômicos buscam obter a maior vantagem possível no decorrer das transações, ainda que isso implique perdas aos demais agentes, admitindo-se mesmo a deflagração de condutas antiéticas (VALLE et al., 2002). Sendo assim, essas empresas podem cotar produtos similares ao pedido para obter vantagem econômica frente aos concorrentes e ao contratante, isto poderia acarretar a compra de produtos sem utilidade e obsoletos.

Diante desse resultado, cabe ao órgão comprador especificar bem os produtos a serem cotados para se salvaguardar de atitudes oportunistas dos fornecedores. Para Jones et al. (2007) e Beuter (2005), as especificações dos produtos se configuram como uma das principais dificuldades desse tipo de compra, sendo ele eficiente apenas para produtos que possam ser descritos com exatidão.

Esse maior oportunismo aliado ao maior conhecimento expressado pela maior média do fator racionalidade limitada pode trazer o problema de ações oportunistas por causa da assimetria de informações. Segundo Sifert Filho (1996), a assimetria informacional se configura como uma das principais causas da ocorrência de custos de transação, em virtude da presença, nos agentes econômicos, do oportunismo. Sendo assim, por esses agentes terem conhecimento da legislação e, consequentemente, das suas possíveis brechas e terem maior conhecimento técnico do produto em oferta, cria-se uma assimetria entre agente e contratante que pode ser prejudicial ao interesse 
público, em que ele poderá comprar um produto que não condiz com o necessário.

Quanto aos maiores escores no fator incerteza, por ele ser, segundo Arbage (2004), de difícil previsão, não pode se configurar como um potencial risco aos contratos. Porém pode-se ressaltar que essa alegação de não cumprimento de contrato por eventos imprevisíveis como fenômenos naturais, econômicos e de contratação de frete pode ser uma desculpa para mascarar uma ineficiência no cumprimento dos prazos acertados.

Quanto às características descritas na Tabela 6, observa-se que esse grupo é constituído por empresas com menor tempo de mercado, o que pode sugerir que contratos com empresas menos consolidadas podem trazer maiores riscos aos contratos. Outro dado importante é que essas empresas têm faturamento médio menor do que os outros grupos, o que caracteriza maior risco de empresas de menor porte. Essas empresas também têm, na composição do seu faturamento, maior participação de vendas a órgãos públicos. E um fator que pode ser uma vantagem para os órgãos públicos é que essas empresas são menos vitoriosas em licitações do que as empresas do grupo de menor risco.

Ao analisar os resultados deste grupo percebe-se que existe um alto risco ligado às compras através desta modalidade. Isso foi observado por Smeltzer (2003), quando afirmou que, embora os leilões reversos se configurem muito atrativos para vendedores e compradores, eles apresentam vários riscos.

Para ele o fato de o leilão reverso usar, como decisão de compra, apenas o menor preço para a próxima compra nenhuma lealdade foi desenvolvida. Outro risco apontado é o fato de, no calor na disputa e levados por um sentimento de busca da vitória a qualquer preço, os licitantes poderem lançar um preço abaixo do seu custo e não conseguir cumpri-lo posteriormente. Quando isso acontece o fornecedor tenta se desvincular do acordo, reduzindo assim a velocidade do processo de aquisição, o que acarreta maiores custos de transação para o comprador e impossibilita o vendedor de transações futuras.

\subsubsection{Grupo 3-Risco Moderado}

Este grupo é formado por $32,21 \%$ das empresas licitantes. Possui a menor média em incerteza e a me- nor busca por frequência nas transações. Porém nos outros fatores elas possuem uma posição intermediária, apresentando assim maior risco do que o grupo $1 \mathrm{e}$ menor risco do que o grupo 2 .

O fato de esse grupo ter a melhor média no fator incerteza, não o credencia a ser considerado de baixo risco, já que esse é um ponto que não pode ser definido como risco, devido a sua imprevisibilidade, por isso, esse evento pode ser encarado mais como um processo de sorte do que de eficiência dessas empresas. Por outro lado, ter a pior média em frequência não o torna o grupo de risco, pois a falta de frequência não se traduz em maior oportunismo dos agentes.

Assim, este grupo não deixa bem definido se possui alto ou baixo risco, visto que grande parte de suas características são intermediárias aos grupos 1 e 2. Esses fatores levaram-no à classificação de risco moderado.

\section{Conclusões}

Em decorrência da interpretação dos resultados, foi possível classificar três grupos distintos de fornecedores para a organização pesquisada, em decorrência da mensuração do grau de risco dos contratos e dos preceitos da teoria dos custos de transação.

O grupo de alto risco obteve maiores escores de oportunismo, racionalidade limitada, incerteza $e$ especificidade dos ativos, enquanto o grupo de baixo apresentou o menor grau de especificidade dos ativos, oportunismo e racionalidade limitada, e maior frequência nos contratos. Portanto, conclui-se que este grupo é formado por empresas mais confiáveis para a realização de transações.

Deve-se ressaltar que, por limitações impostas pela legislação vigente aos processos licitatórios, os órgãos públicos não têm o poder de escolha na contratação de empresas, por isso, é importante que eles criem salvaguardas para se defender de possíveis atitudes oportunistas, já que a maioria das organizações apresenta alto risco de cometerem atitudes antiéticas.

Sendo assim, é importante que a especificação dos produtos licitados não deem margem para a cotação de produtos similares ou de qualidade inferior. Outro fator importante para a inibição dessa prática oportunista é a aplicação das sanções previstas na 
lei, mesmo que isso implique em maiores custos de transação.

\section{REFERÊNCIAS}

AGUS, A.; BARKER, S.; KANDAMPULLY, J. An exploratory study of service quality in the Malaysian public service sector. International Journal of Quality \& Reliability Management, v. 24, n. 2, p. 177 190, 2007.

ALVES, M. A.; STADUTO, J. A. R. Análise da estrutura de governança: o caso cédula do produtor rural (CPR). $2^{\circ}$ CONGRESSO INTERNACIONAL DE ECONOMIA E GESTÃO DE NEGÓCIOS AGROALIMENTARES,

Anais... Ribeirão Preto, 1999.

ARBAGE, A. P. Custos de transação e seu impacto na formação e gestão da cadeia de suprimentos: estudo de caso em estruturas de governança híbridas do sistema agroalimentar no rio grande do sul. Porto Alegre, RS: UFRS, 2004. (TESE D.S)

AZEVEDO, P. F. Nova Economia Institucional: referencial geral e aplicações para a agricultura. Revista de Economia Agrícola, São Paulo, v. 47, n. 1, p. 33-52, 2000.

BALESTRIN, A.; ARBAGE A. P. A perspectiva dos custos de transação na formação de redes de cooperação. RAEeletrônica, São Paulo, v. 6, n. 1, jan.-jun. 2007.

BEALL, S. et al. The Role of Reverse Auctions in

Strategic Sourcing, Tese de Doutorado. Arizona State University, 2003.

BEUTER, R. European Public Procurement Reform: Main Innovations in the Public Sector Directive - A Preliminary Assessment. EIPAScope, Maastricht, Netherlands. n. 3, p. 5-11, 2005.

CARTER, C. R., KAUFMANN, L., BEALL, S., CARTER, P., HENDRICK, T.; PETERSEN, K. J. Reverse auctions-grounded theory from the buyer and supplier perspective. Transportation Research Part E: Logistics and Transportation Review, v. 40, n. 3, p. 229254, 2004.
CARTER, C. R.; STEVENS, C. K. S. Electronic reverse auction configuration and its impact on buyer price and supplier perceptions of opportunism: A laboratory experiment. Journal of Operations Management, v. 25, n. 5, p. 1035-1054, 2007.

COELHO, E. M. Governo eletrônico e seus impactos na estrutura e na força de trabalho das organizações públicas. Revista do Serviço Público, Brasília, DF, abr.jun. 2001.

DINIZ, E. A.; STOFFEL, J. A.; GOEBEL, M. A. Licitações e compras públicas de alimentos numa perspectiva da nova economia institucional: o caso Toledo (PR). Revista Informe Gepec, jul.-dez., 2004.

EVERITT, B. S. Cluster analysis. London: Hodder \& Stoughton, 1993. $170 \mathrm{p}$.

FERNANDEZ, N. M. et al. Aligning leadership and competences in recruitment and staff development: an empirical analysis in the context of regional public administration. International Journal of Public, Sector Performance Management, v. 1, n. 2, p. 167-182, 2008.

FERREIRA, M. A. M.; BRAGA, M. J. Desempenho das cooperativas na indústria de laticínios do Brasil: uma abordagem por grupos estratégicos. R. Adm., São Paulo, v. 42, n. 3, jul.-ago.-set. 2007.

GATTIKER, T. F.; HUANG, X.; SCHWARZ, J. L. 'Why do Sellers Dislike Internet Reverse Auctions?: Some Experimental Results. In: Proceedings of the 16th Annual North American Research Symposium Tempe, AZ, Março 17-19, 2005. p. 183-204.

GIL, A. C. Como Elaborar Projeto de Pesquisa. 4. ed. São Paulo: Atlas, 2002.

HAIR, J. F.; ANDERSON, R E.; TATHAM, R. L.; BLACK, W. C.; Análise multivariada de dados. 5. ed. Porto Alegre. Bookman, 2005. 593 p.

HIRATUKA, C. Estruturas de coordenação e relações interfirmas: uma interpretação a partir da teoria dos custos de transação e da teoria Neo Schumpeteriana.

Economia de Empresas, São Paulo, v. 4, n. 1, p. 17-32, jan.-mar. 1997. 
HOUSTON, D. J. "Walking the Walk" of Public Service Motivation: Public Employees and Charitable Gifts of Time, Blood, and Money. Journal of Public Administration Research and Theory, v. 16, n. 1, p. 67-86, 2006.

HOUSTON, D. J. Public-Service Motivation: A Multivariate Test. Journal of Public Administration Research and Theory, v. 10, n. 4, p. 713-728, 2000.

JAP, S. D. An exploratory study of the introduction of online reverse auctions. Journal of Marketing, p. 96107, 2003.

JONES, S.; HACKNEY, R.; IRANI Z. E-government: an e-reverse auction case study. Electronic Government, an International Journal, v. 4, n. 4, p. 412-422, 2007.

JUNIOR, R. J. C. MACHADO, R. T. M. Acordos contratuais sob a ótica da economia dos custos de transação: o caso de uma agroindústria canavieira no estado de Pernambuco. IV CONGRESSO INTERNACIONAL DE ECONOMIA E GESTÃO DE REDES AGROALIMENTARES. Ribeirão Preto - Outubro de 2003. Anais... Ribeirão Preto, 2003.

\section{LAUREANO, F. H. G. C. A indústria de gás natural} e as relações contratuais uma análise do caso brasileiro. Dissertação de Mestrado em engenharia da UFRJ. Rio de Janeiro, 2005.

LOESCH, A.; LAMBERT, J. S. E-Reverse Auctions Revisited: An Analysis of Their Context, Buyer-Supplier Relations, and Information Behaviour. Journal of Supply Chain Management, v. 43, n. 4, p. 47-63, 2007.

LUCCI, C. R. Custos de transação no ambiente portuário: uma aplicação da nova economia institucional para o porto de santos. VII Semead, São Paulo, 2004. Anais... São Paulo, 2004.

MANLY, B.F.J. Multivariate statistical methods - a primer. New York: Chapman and Hall, 1986. 159 p.

MARTIN, M. Assessing Technology Transfer and Business Development Potential: Technology Cluster Analysis.

Economic Development Quarterly, v. 18, n. 2, p.
168-173, 2004.

MARTINS, P. C. O Sistema Agroindustrial do Leite: Transações e incentivos a adoção de tecnologias. Anais... $2^{\circ}$ Congresso Internacional de Economia e Gestão de negócios agroalimentares, Ribeirão Preto: 1999.

MENEZES, R. A.; SILVA, R. B. da; LINHARES, A. Leilões eletrônicos reversos multiatributo: uma abordagem de decisão multicritério aplicada às compras públicas brasileiras. Revista de Administração Contemporânea, [on-line], v. 11, n. 3, p. 11-33, 2007. MODREGO-RICO, A.; BARGE-GIL, A.; NÚÑEZSÁNCHEZ, R. Developing indicators to measure technology institutes' performance. Research Evaluation, v. 14, n. 2, p. 177-184, 2005.

NORTH, D. C. Custos de transação, instituições e desempenho econômico. Cambridge: University Press, 1994.

PINTO JÚNIOR, H. Q.; PIRES, M. C. P. Assimetria de informações e problemas regulatórios. Nota Técnica n. 9: ANP, fevereiro, 2000.

REZENDE, I. A. C. et al. A Eficácia dos contratos de serviços por Pregão( leilões reversos): um estudo nas licitações públicas de serviços continuados. Anais... $7^{\circ}$ Congresso USP de contabilidade e controladoria. São Paulo, 2007.

\section{ROSENBERG, A.; TURVEY, C. G. Obtaining} Management Profiles of Ontario Swine Producers Through Cluster Analysis. Canadian Journal of Agricultural Economics: Revue canadienne, v. 38, n. 4, p. 1021-1021, 1990.

SANTANA, Z. A.; ROCHA, W. Custo total de Propriedade: um estudo da sua aplicação a lei de licitações. $7^{\circ}$ CONGRESSO USP DE CONTABILIDADE E CONTROLADORIA. Anais... São Paulo, 2007.

\section{SANTOS, R. T. Coordenação de Investimentos} e Políticas de Introdução da concorrência na indústria de gás natural: elementos para análise de casos no Brasil. Dissertação de Mestrado, Instituto de Economia - UFRJ. Rio de Janeiro, 2001. 
SILVA, A. A.; FERREIRA R. T. Pregões Eletrônicos Realizados pela Prefeitura Municipal de Fortaleza em 2006: um ensaio econométrico. Premio Sefin de finanças municipais, Fortaleza: 2007.

\section{SMELTZER, L. R.; KARR, A. Electronic reverse} auctions: promises, risks and conditions for success. Industrial Marketing Management, v. 32, n. 6, p. 481-488, 2003.

SOUSA, E. L. L.; AZEVEDO, P. F.; SAES, M. S. M. Competitividade do sistema agroindustrial do milho. Brasília, DF: Trabalho Técnico, 1998.

TAYLOR, J. The impact of public service motives on work outcomes in australia: a comparative multi-dimensional analysis. Journal of Public Administration, 2007.

TRIOLA, M. F. Introdução à estatística. 9. ed. Rio de Janeiro: LTC, 2005.

VALLE, M. G.; FILHO, S. S. Redes de inovação tecnológica: Aportes da economia evolucionista e da nova economia institucional. $3^{\circ}$ Congresso Internacional de Economia e Gestão de negócios agroalimentares, Anais... Ribeirão Preto, 2001.

VALLE, M. G.; BONACELLI, M. B. M.; FILHO, S. S. Aportes da Economia Evolucionista e da Nova Economia Institucional na Constituição de Arranjos Institucionais de Pesquisa. XXII Simpósio de Gestão da Inovação Tecnológica. Anais ... Salvador, BA, 2002.

VASCONCELLOS, F. Licitação pública: análise dos aspectos relevantes do Pregão. [2008]. Disponível em: < http://www.ccj.ufpb.br/primafacie/prima/artigos/n7/ licitacao.pdf>. Acesso em: 25 fev. 2008.

\section{VERGARA, S. C. Projetos e relatórios de pesquisa} em administração. 3. ed. São Paulo: Atlas, 2005.

WILLIAMSON, O. E. The economics institutions of capitalism. Free Press, 1985.

WILLIAMSON, O. E.; AOKI, Masakiro; GUSTAFSSON, $B$. The Firm as a Nexus of Treaties. Londres: Sage Publications Inc. 1990.
XIAOQING, Q. A grey cluster analysis of livability in residential district planning. International Conference on Grey Systems and Intelligent Services, 2007. GSIS 2007. IEEE International Conference on. IEEE, 2007. p. 356-359.

ZERBINATI, S.; SOUITARIS, V. Entrepreneurship in the public sector: a framework of analysis in European local governments. Entrepreneurship \& Regional Development, 2005.

ZYLBERSZTAJN, D. Economia das Organizações. In: ZYLBERSZTAJN, D.; NEVES, M. F. (Org.). Economia e gestão de negócios agroalimentares. São Paulo: Pioneira, 2000.

ZYLBERSZTAJN, D. Estruturas de governança e coordenação do agribusiness: uma aplicação da nova economia das instituições. Dissertação (Livre Docência em Administração). Faculdade de Economia, Administração e Contabilidade, USP, São Paulo, 1995.

ZYLBERSZTAJN, D. Organização ética: um ensaio sobre comportamento e estrutura das organizações. Revista de Administração Contemporânea (RAC), Rio de Janeiro, v. 6, n. 2, p. 123-143, maio-ago. 2002.

WILLIAMSON, O. The economic institutions of capitalism: firms, markets and relational contracting. New York: Free, 1985. 